\title{
Effects of Fat on Glucose Uptake and Utilization in Patients with Non-Insulin-dependent Diabetes
}

\author{
Guenther Boden and Xinhua Chen \\ Division of Endocrinology/Metabolism and the General Clinical Research Center, Temple University School of Medicine, \\ Philadelphia, Pennsylvania 19140
}

\begin{abstract}
It was the aim of this study to determine whether FFA inhibit insulin-stimulated whole body glucose uptake and utilization in patients with non-insulin-dependent diabetes. We performed five types of isoglycemic $(\sim 11 \mathrm{mM})$ clamps: (a) with insulin; (b) with insulin plus fat/heparin; (c) with insulin plus glycerol; $(d)$ with saline; $(e)$ with saline plus fat/heparin and two types of euglycemic $(\sim 5 \mathrm{mM})$ clamps: (a) with insulin; (b) with insulin plus fat/heparin. During these studies, we determined rates of glucose uptake, glycolysis (both with $3\left[{ }^{3} \mathbf{H}\right]$ glucose), glycogen synthesis (determined as glucose uptake minus glycolysis), carbohydrate oxidation (by indirect calorimetry) and nonoxidative glycolysis (determined as glycolysis minus carbohydrate oxidation). Fat/heparin infusion did not affect basal glucose uptake, but inhibited total stimulated (insulin stimulated plus basal) glucose uptake by $40-50 \%$ in isoglycemic and in euglycemic patients at plasma FFA concentration of $\sim 950$ and $\sim 550 \mu M$, respectively. In isoglycemic patients, the 40-50\% inhibition of total stimulated glucose uptake was due to near complete inhibition of the insulin-stimulated part of glucose uptake. Proportional inhibition of glucose uptake, glycogen synthesis, and glycolysis suggested a major FFA-mediated defect involving glucose transport and/or phosphorylation. In summary, fat produced proportional inhibitions of insulin-stimulated glucose uptake and of intracellular glucose utilization. We conclude, that physiologically elevated levels of FFA could potentially be responsible for a large part of the peripheral insulin resistance in patients with non-insulin-dependent diabetes mellitus. ( $J$. Clin. Invest. 1995. 96:1261-1268.) Key words: free fatty acids • glycogen synthesis • glycolysis • nonoxidative glycolysis $\cdot$ glucose oxidation
\end{abstract}

\section{Introduction}

There is considerable evidence indicating that fat, either in the form of excessive storage (obesity) or as fat feeding, is associated with insulin resistance. For instance, more than $80 \%$ of patients with non-insulin-dependent diabetes mellitus

Address correspondence to Guenther Boden, Temple University Hospital, 3401 North Broad Street, Philadelphia, PA 19140. Phone: 215-7078984; FAX: 215-707-1560.

Received for publication 14 April 1995 and accepted in revised form 25 June 1995.

J. Clin. Invest.

(C) The American Society for Clinical Investigation, Inc. 0021-9738/95/09/1261/08 \$2.00

Volume 96, September 1995, 1261-1268
(NIDDM $)^{1}$ are obese and insulin resistant. In addition, fat feeding has been shown to cause insulin resistance in healthy volunteers (1) and diabetes in rats with impaired $\beta$ cell function (2).

There are reasons to believe that plasma FFA are the cause for the association between fat and insulin resistance. In normal subjects, recent work from several laboratories has established that fatty acids exerted acute inhibitory actions on insulin-stimulated glucose uptake (for review see references 3-5). These findings could provide a key for a better understanding of the role of fat in the pathogenesis of insulin resistance in obese subjects and in patients with NIDDM, many of whom have elevated plasma FFA levels (6). In contrast to these studies with normal subjects, however, efforts by several investigators to find inhibitory effects of fatty acids on insulin-stimulated glucose uptake in patients with NIDDM (7-9) and in obese nondiabetic women (10) have been unsuccessful. This has led to the conclusion that in patients with NIDDM, excessive utilization of FFA cannot be held responsible for their insulin resistance (7). In all these studies, the effect of fatty acids plus insulin, on glucose uptake, was tested for only $2 \mathrm{~h}$. As shown by us, the inhibitory effect on glucose uptake only becomes apparent after 3-4 h of fat infusion (3). Thus, the failure to observe inhibitory effects may have been the result of inappropriately short lipid plus insulin infusions.

In the present study, we have, therefore, investigated effects of physiological elevations of plasma FFA concentrations on insulin-stimulated whole body glucose uptake in patients with NIDDM. In addition, we have examined effects of FFA on glucose fluxes through all major pathways of intracellular glucose metabolism including glycogen synthesis, glycolysis, carbohydrate ( $\mathrm{CHO}$ ) oxidation, and nonoxidative glycolysis using methods which we have recently validated $(5,11)$.

\section{Methods}

\section{Subjects}

The clinical characteristics of the patients with NIDDM participating in seven study protocols are shown in Table I. All patients had been treated with sulfonylurea drugs and 13 received in addition small doses of NPH insulin (5-15 $\mathrm{U})$ at bedtime. Insulin and all other medications were discontinued the day before the studies. The patients' weights were stable for at least $2 \mathrm{mo}$, their diets contained a minimum of 250 grams/ $\mathrm{d}$ of carbohydrate for at least $2 \mathrm{~d}$ before the studies. Informed written consent was obtained from all after explanation of the nature, purpose, and potential risks of these studies. The study protocol was approved by the Institutional Review Board of Temple University Hospital.

1. Abbreviations used in this paper: $\mathrm{CHO}$, carbohydrate; FFM, fat free mass; HGP, hepatic glucose production; NIDDM, non-insulin-dependent diabetes mellitus. 


\begin{tabular}{|c|c|c|c|c|c|c|c|}
\hline & \multicolumn{2}{|c|}{ Euglycemia } & \multicolumn{5}{|c|}{ Isoglycemia } \\
\hline & Insulin & Insulin \& fat & Insulin & Insulin \& fat & Insulin \& glycerol & Saline & Saline \& fat \\
\hline $\operatorname{Sex}(\mathbf{M} / \mathbf{F})$ & $1 / 8$ & $2 / 3$ & $2 / 5$ & $2 / 5$ & $2 / 2$ & $0 / 4$ & $0 / 4$ \\
\hline Age (yr) & $65.9 \pm 3.9$ & $59.4 \pm 4.2$ & $72.0 \pm 2.7$ & $64.9 \pm 3.6$ & $75 \pm 6.6$ & $64.7 \pm 2.4$ & $64.7 \pm 2.4$ \\
\hline Height (cm) & $160 \pm 1.4$ & $175 \pm 4.2$ & $164 \pm 2.8$ & $166 \pm 2.2$ & $163 \pm 6.4$ & $165 \pm 2.3$ & $165 \pm 2.3$ \\
\hline Weight (kg) & $78.4 \pm 7.3$ & $99.3 \pm 8.7$ & $68.0 \pm 2.8$ & $75.6 \pm 3.1$ & $74 \pm 5.8$ & $84.0 \pm 2.2$ & $84.0 \pm 2.2$ \\
\hline FFM (kg) & $46.8 \pm 4.6$ & $70.7 \pm 6.2$ & $45.0 \pm 4.3$ & $52.0 \pm 3.0$ & $50.9 \pm 7.0$ & $55.0 \pm 5.0$ & $55.0 \pm 5.0$ \\
\hline BMI $\left(\mathrm{kg} / \mathrm{m}^{2}\right)$ & $30.4 \pm 2.4$ & $32.2 \pm 1.8$ & $25.4 \pm 0.6$ & $27.5 \pm 1.2$ & $28.0 \pm 0.3$ & $33.0 \pm 2.0$ & $33.0 \pm 2.0$ \\
\hline
\end{tabular}

BMI $=$ body mass index.

\section{Experimental design}

All subjects were admitted to Temple University Hospital's General Clinical Research Center on the morning of the studies which began at $\sim$ 8:00 a.m. after an overnight fast with the subjects reclining in bed. A short polyethylene catheter was inserted into an antecubital vein for infusion of test substances. Another catheter was placed into a contralateral forearm vein for blood sampling. This arm was wrapped with a heating blanket $\left(\sim 70^{\circ} \mathrm{C}\right)$ to arterialize venous blood. We have found in preliminary experiments that this resulted in near identical arterial and venous forearm blood glucose concentrations. Three different types of studies were performed.

Euglycemic-hyperinsulinemic clamps. We performed nine studies with insulin and five studies with insulin plus fat/heparin. To lower plasma glucose from the prevailing hyperglycemia $(\sim 11.5 \mathrm{mM})$ into the euglycemic range, regular human insulin (Humulin R; E. Lilly \& Co., Indianapolis, IN) was infused intravenously at a rate of $6 \mathrm{pmol} /$ $\mathrm{kg}$ per min for $5 \frac{1}{2} \mathrm{~h}$ starting at $-90 \mathrm{~min}$. Glucose concentrations were clamped at $\sim 5 \mathrm{mM}$ starting at $0 \mathrm{~min}$ for $4 \mathrm{~h}$ by a feedback-controlled glucose infusion. In the studies with fat/heparin, Liposyn II (Abbott Laboratories, N. Chicago, IL) a $20 \%$ triglyceride emulsion (10\% safflower, $10 \%$ soybean oil) containing 2.14 grams glycerol $/ 100 \mathrm{ml}$ plus heparin $(0.4 \mathrm{U} / \mathrm{kg}$ per $\mathrm{min})$ was infused at rate of $1.5 \mathrm{ml} / \mathrm{min}$ for $4 \mathrm{~h}$ together with insulin and glucose.

Isoglycemic-hyperinsulinemic clamps. Seven studies were performed with insulin, seven with insulin plus fat/heparin, and four with insulin plus glycerol. The glycerol infusion studies were needed as a second control because plasma glycerol levels rose during all Liposyn II infusions ( see Table II). Glucose concentrations were clamped from 0-240 min at these patient's prevailing plasma glucose concentrations $(\sim 11.5 \mathrm{mM})$ by a feedback controlled glucose infusion. The remainder of the protocol was the same as that used in the euglycemic clamps.

Isoglycemic clamps without insulin infusion. Four patients with NIDDM were studied twice, once with saline and once with fat/heparin. Liposyn II plus heparin or saline, both without insulin, were infused for $4 \mathrm{~h}$ starting at $0 \mathrm{~min}$. Glucose concentrations were clamped at $\sim 11$ $\mathrm{mM}$ with a variable rate glucose infusion.

\section{Measurements}

Glucose turnover. Glucose turnover was determined with $3\left[{ }^{3} \mathrm{H}\right]$ glucose. The tracer infusion ( $40 \mu \mathrm{Ci}$ over $1 \mathrm{~min}$ followed by $0.4 \mu \mathrm{Ci} / \mathrm{min}$ ) was started $90 \mathrm{~min}$ before initiation of the clamp to assure isotope equilibration. Glucose was isolated from blood for determination of $3\left[{ }^{3} \mathrm{H}\right]$ glucose specific activity as described (12). Changes in specific activity during hyperinsulinemia were avoided by adding $3\left[{ }^{3} \mathrm{H}\right]$ glucose to the unlabeled glucose which was infused at variable rates to maintain euglycemia or isoglycemia (13). Rates of total body glucose appearance and disappearance were calculated using Steele's equation for steady state conditions (14).

Glycolytic flux. Glycolytic flux was determined according to Rossetti and Giaccari with minor modifications (15). Tritium in the 3-carbon position of glucose is lost into water during glycolysis. We have recently validated the assumption that the rate of tritiated water formation in human plasma reflects the intracellular detritiation of $3\left[{ }^{3} \mathrm{H}\right]$ glucose (11). The rate of glycolysis was obtained by dividing the whole body ${ }^{3} \mathrm{H}_{2} \mathrm{O}$ production rate by the specific activity of its precursor i.e., plasma $3\left[{ }^{3} \mathrm{H}\right]$ glucose (11).

Glycogen synthesis. Whole body glycogen synthesis rates were obtained by subtracting rates of glycolysis from rates of glucose uptake. We have documented the validity of this noninvasive approach by demonstrating that results obtained with this method were comparable to rates of glycogen synthesis determined by incorporation of tritium from $3\left[{ }^{3} \mathrm{H}\right]$ glucose into muscle glycogen (11) and to rates of glycogen synthesis calculated from glycogen synthase activity and glucose-6-phosphate concentrations in muscle biopsies $(5,11)$.

$\mathrm{CHO}$ and lipid oxidation. $\mathrm{CHO}$ and lipid oxidation were determined by indirect calorimetry (16) with a metabolic measurement cart (Beckman Instruments, Inc., Palo Alto, CA). Rates of protein oxidation were estimated from the urinary $\mathrm{N}$ excretion after correction for changes in urea $\mathrm{N}$ pool size (17). Rates of protein oxidation were used to determine the nonprotein respiratory quotient (npRQ). It was assumed that for each gram of $\mathrm{N}$ excreted in the urine, 6.02 liters of $\mathrm{O}_{2}$ were consumed and 4.75 liters of $\mathrm{CO}_{2}$ were produced $(\mathrm{RQ}=0.79)$. Rates of $\mathrm{CHO}$ and fat oxidation were determined with the npRQ tables of Lusk, which are based on an npRQ of 0.707 for $100 \%$ fat oxidation and 1.00 for $100 \%$ CHO oxidation.

Hepatic glucose output. Hepatic glucose output was calculated as the difference between the isotopically determined rates of glucose appearance and the rates of glucose infused to maintain euglycemia or isoglycemia during the clamps.

Nonoxidative glycolysis (lactate/alanine flux). Nonoxidative glycolysis (lactate/alanine flux) was calculated as the difference between rates of total body glycolysis and $\mathrm{CHO}$ oxidation.

Leg blood flow. Leg blood flow was determined by venous occlusion plethysmography with a mercury strain gauge apparatus (model EC5R; Hokanson Inc., Issaquah, WA) (18).

Body composition. Body composition was determined by underwater weighing with correction for residual lung volume (19) which was determined after immersion in a sitting position with a closed circuit $\mathrm{O}_{2}$ dilution method (19).

Analytical procedures. Plasma glucose was measured with a glucose analyzer (Beckman Instruments, Inc.). Serum insulin (20) and glucagon (21) were determined by radioimmunoassay. Blood urea nitrogen (22) was measured enzymatically. Urinary nitrogen was measured by the method of Kjeldahl (23). Fatty acids were determined by gas chromatography (model 5730A, Hewlett-Packard Co., Palo Alto, CA) as the sum of seven individual fatty acids (myristate, palmitate, palmitoleate, stearate, oleate, linoleate, and arachidonate). Heptadecanoic acid was used as internal standard. Glycerol was measured colorimetrically (24).

Calculations and statistical analysis. All data were expressed as the mean $\pm S E M$. Rates of glucose uptake, glycogen synthesis, glycolysis, nonoxidative glycolysis, and $\mathrm{CHO}$ oxidation were expressed per kilogram fat free mass (FFM) since most of the intravenous-infused glucose 


\begin{tabular}{|c|c|c|c|c|c|}
\hline & Insulin & Glucagon & Glucose & FFA & Glycerol \\
\hline & $p M$ & $n g / m l$ & $m M$ & $\mu M$ & $m M$ \\
\hline \multicolumn{6}{|c|}{ Isoglycemic clamps without insulin } \\
\hline Basal & $183 \pm 63$ & $117 \pm 15$ & $11.2 \pm 0.2$ & $601 \pm 41$ & $0.10 \pm 0.01$ \\
\hline Saline & $165 \pm 60$ & $101 \pm 10$ & $10.8 \pm 0.2$ & $526 \pm 104$ & $0.10 \pm 0.01$ \\
\hline Basal & $130 \pm 60$ & $125 \pm 20$ & $11.1 \pm 0.7$ & $674 \pm 116$ & $0.10 \pm 0.01$ \\
\hline Saline + fat & $152 \pm 58$ & $124 \pm 21$ & $11.0 \pm 0.3$ & $1175 \pm 57$ & $0.47 \pm 0.06$ \\
\hline \multicolumn{6}{|c|}{ Isoglycemic clamps with insulin } \\
\hline Basal & $201 \pm 62$ & $80 \pm 17$ & $11.4 \pm 0.8$ & $539 \pm 97$ & $0.08 \pm 0.01$ \\
\hline Insulin & $921 \pm 216$ & $65 \pm 17$ & $11.0 \pm 0.3$ & $46 \pm 16$ & $0.03 \pm 0.01$ \\
\hline Insulin + fat & $960 \pm 204$ & $73 \pm 15$ & $11.5 \pm 0.1$ & $1064 \pm 170$ & $0.54 \pm 0.08$ \\
\hline Insulin + glycerol & $903 \pm 178$ & & $11.6 \pm 0.9$ & $28 \pm 19$ & $0.35 \pm 0.06$ \\
\hline \multicolumn{6}{|c|}{ Euglycemic clamps with insulin } \\
\hline Basal & $131 \pm 32$ & $89 \pm 12$ & $11.9 \pm 1.2$ & $514 \pm 74$ & $0.11 \pm 0.02$ \\
\hline Insulin & $545 \pm 48$ & $63 \pm 12$ & $4.8 \pm 0.1$ & $95 \pm 19$ & $0.05 \pm 0.01$ \\
\hline Insulin + fat & $572 \pm 144$ & $79 \pm 21$ & $5.2 \pm 0.2$ & $1450 \pm 79$ & $0.59 \pm 0.08$ \\
\hline
\end{tabular}

Basal: values obtained during clamping. All other values were obtained during the last hour of clamping.

is metabolized in muscle (25). Statistical significance was assessed using ANOVA and Student's two-tailed paired or unpaired $t$ test where applicable.

\section{Results}

Blood hormone and substrate levels (Table II). Serum insulin concentrations during the last hour of isoglycemic clamps without insulin were $165 \pm 60$ and $152 \pm 58 \mathrm{pM}$ with saline and with fat infusions, respectively. Serum insulin concentration during isoglycemic clamps with insulin were $921 \pm 216,960 \pm 204$, and $903 \pm 178 \mathrm{pM}$ with insulin, insulin and fat, and insulin and glycerol, respectively. Insulin concentrations during euglycemic clamps with insulin were $545 \pm 48$ and $572 \pm 144 \mathrm{pM}$ for studies with insulin and with insulin and fat, respectively.

Plasma glucose concentrations were clamped at concentrations of between 11 and $12 \mathrm{mM}$ in all isoglycemic studies and at $\sim 5 \mathrm{mM}$ in the euglycemic studies.

Last hour plasma FFA concentrations during isoglycemic clamps without insulin were $526 \pm 104$ and $1,175 \pm 57 \mu \mathrm{M}$, respectively, for studies without and with fat. During isoglycemic clamps with insulin, plasma FFA concentrations were $46 \pm 16$, $1,064 \pm 170$, and $28 \pm 19 \mu \mathrm{M}$, respectively, for studies with insulin, insulin plus fat, and insulin plus glycerol.

Basal plasma glycerol concentrations were $0.1 \pm 0.01 \mathrm{mM}$. Glycerol concentrations decreased during insulin infusions to $0.03 \pm 0.01$ and $0.05 \pm 0.01 \mathrm{mM}$ during iso- and euglycemic clamping, respectively. Serum glycerol concentrations increased during fat infusions to $0.47 \pm 0.06$ and $0.54 \pm 0.08 \mathrm{mM}$, respectively, during iso- and euglycemic clamping. During glycerol infusions, last hour plasma glycerol concentration was $0.35 \pm 0.06 \mathrm{mM}$ which was not significantly different from the glycerol concentrations during the fat infusion studies.

Effect of fat on basal glucose uptake (Fig. 1). To investigate whether fat can inhibit basal glucose uptake, we performed isoglycemic clamps in four patients with NIDDM with either fat/heparin or with saline alone. Postabsorptive glucose uptake decreased nonsignificantly by $16 \%$ (from $21.9 \pm 1.9$ to $18.3 \pm 1.4$ $\mu \mathrm{mol} / \mathrm{kg}$ FFM per min, NS) during the 4-h fat infusion and by $16 \%$ (from $17.7 \pm 2.4$ to $14.8 \pm 0.7 \mu \mathrm{mol} / \mathrm{kg}$ FFM per min, NS) during saline infusion. The lack of difference between fat and saline infusions indicated that fat did not inhibit glucose uptake at basal glucose and insulin concentrations.

Effect of fat on glucose uptake stimulated by insulin (Fig. 2, Table III). To investigate whether fat can inhibit insulinstimulated glucose uptake, we performed hyperinsulinemic clamps. To examine whether the effects of fat were different in uncorrected diabetes as compared to diabetes compensated

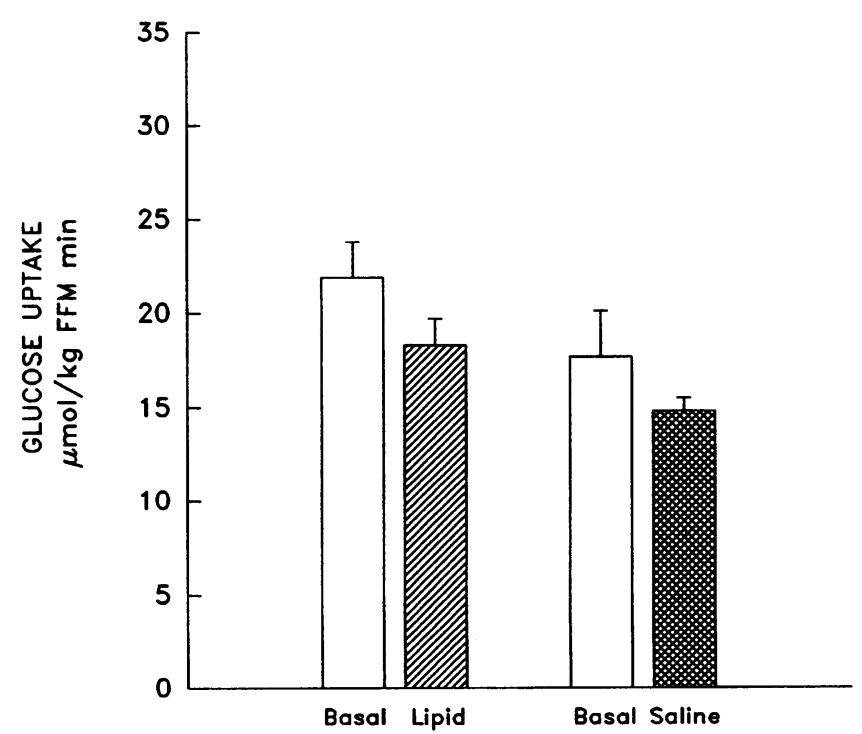

Figure 1. Effect of fat or of saline on basal glucose uptake. Basal hyperglycemia ( $\sim 11 \mathrm{mM}$ ) was maintained with a variable glucose infusion. Shown are mean \pm SEM of four studies with fat and four studies with saline infusions. Values are obtained before and at the end of the 4-h studies. All four patients with NIDDM underwent both studies. The decreases in glucose uptake during fat and saline infusions were not statistically significant $(P>0.05)$. 


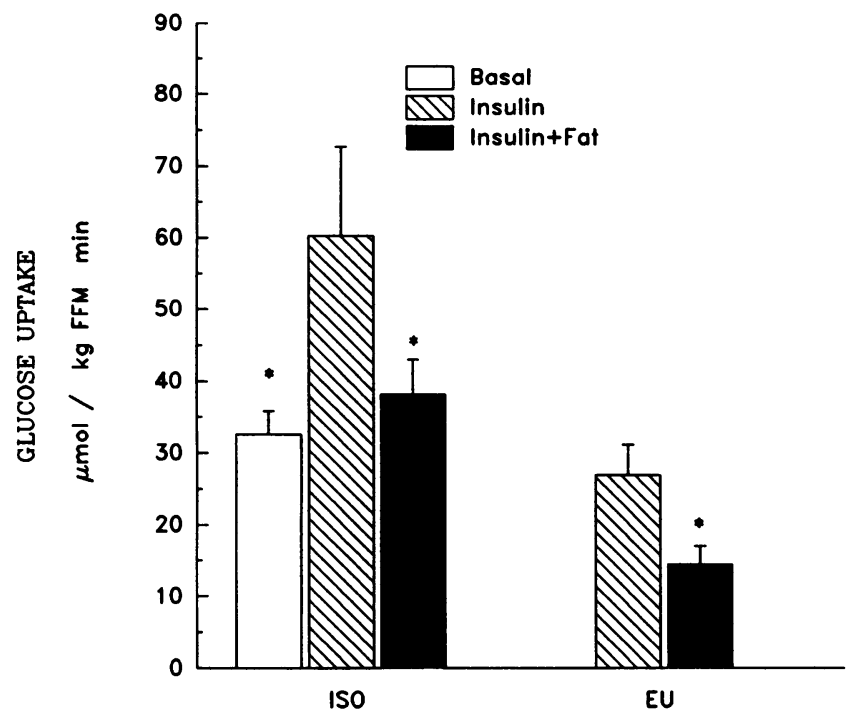

Figure 2. Effects of insulin and of fat plus insulin on glucose uptake during isoglycemic (ISO) and euglycemic $(E U)$ clamps in patients with NIDDM. Shown are mean \pm SEM. Values were obtained at the end of 4-h clamps. Number of studies as in Table III. $* P<0.05$ comparing insulin studies with basal or with insulin plus fat/heparin studies.

by hyperglycemia, we performed these clamps at euglycemic $(\sim 5 \mathrm{mM})$ and at isoglycemic $(\sim 11.5 \mathrm{mM})$ conditions. Fat infused together with insulin decreased total (insulin stimulated plus basal) glucose uptake by $37 \%$ (from 60.3 to $38.2 \mu \mathrm{mol} /$ kg FFM per min, $P<0.05$ ) during isoglycemic clamping. Compared to the insulin plus glycerol controls, the fat-mediated inhibition was $50 \%$ (from 76.3 to $38.2 \mu \mathrm{mol} / \mathrm{kg}$ FFM per min, $P<0.01$ ). During euglycemic clamping, fat decreased glucose uptake by $46 \%$ (from 26.9 to $14.4 \mu \mathrm{mol} / \mathrm{kg}$ FFM per min, $P$ $<0.05)$. The decrease in isoglycemic patients with NIDDM represented an almost complete inhibition $(-86 \%)$ of the insulin stimulated part of glucose uptake. In euglycemic patients,

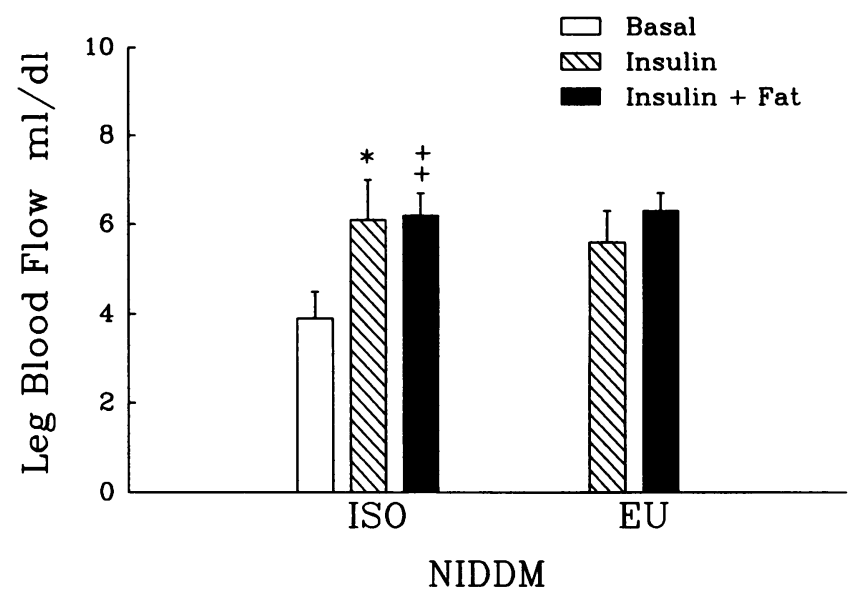

Figure 3. Leg blood flow ( $\mathrm{ml} / \mathrm{dl}$ leg tissue) before (basal) and at the end of isoglycemic-hyperinsulinemic (ISO) and euglycemic-hyperglycemic $(E U)$ clamps in patients with NIDDM. Shown are mean \pm SEM. Number of studies as in Table III. Statistical analysis: $* P<0.05$; $\ddagger P<0.01$ comparing basal vs insulin or basal vs insulin + fat.

we could determine only total (insulin stimulated plus basal) stimulated glucose uptake. Basal glucose uptake could not be determined because insulin had to be infused to lower their glucose concentrations into the euglycemic range; thus, the insulin stimulated part of glucose uptake could not be calculated.

Effect of fat on leg blood flow (Fig. 3). To determine whether fat affected blood flow, we determined leg blood flow during the euglycemic- and isoglycemic-hyperinsulinemic clamps. Basal leg blood flow was $3.9 \pm 0.4 \mathrm{ml} / \mathrm{dl}$ leg tissue in isoglycemic patients. Insulin increased leg blood flow to $5.6 \pm 0.5 \mathrm{ml} / \mathrm{dl}$ during euglycemic clamping and to $6.3 \pm 0.4 \mathrm{ml} /$ $\mathrm{dl}(P<0.05)$ during isoglycemic clamping. Infusion of fat had no significant effect on insulin stimulated leg blood flow during isoglycemic $(6.3 \pm 0.7 \mathrm{ml} / \mathrm{dl})$ or euglycemic clamping $(6.3 \pm 0.4$ $\mathrm{ml} / \mathrm{dl}$ ).

Table III. Glucose Uptake and Utilization during Hyperinsulinemic Clamps

\begin{tabular}{|c|c|c|c|c|c|c|c|c|c|c|c|c|}
\hline & \multicolumn{2}{|c|}{ Glucose uptake } & \multicolumn{2}{|c|}{$\begin{array}{l}\text { Glycogen } \\
\text { synthesis }\end{array}$} & \multicolumn{2}{|c|}{ Glycolysis } & \multicolumn{2}{|c|}{ CHO oxidation } & \multicolumn{2}{|c|}{$\begin{array}{c}\text { Nonoxidative } \\
\text { glycolysis }\end{array}$} & \multicolumn{2}{|c|}{$\begin{array}{l}\text { Hepatic glucose } \\
\text { production }\end{array}$} \\
\hline & Basal & Insulin & Basal & Insulin & Basal & Insulin & Basal & Insulin & Basal & Insulin & Basal & Insulin \\
\hline & \multicolumn{12}{|c|}{$\mu \mathrm{mol} / \mathrm{kg} F F M$ min } \\
\hline \multicolumn{13}{|l|}{ Euglycemic } \\
\hline Insulin & & 26.9 & & 9.7 & & 17.3 & & 11.4 & & 5.9 & & 3.9 \\
\hline (9) & & 3.8 & & 3.1 & & 1.2 & & 1.8 & & 1.3 & & 1.5 \\
\hline Insulin + fat & & 14.4 & & 6.2 & & 8.2 & & 2.6 & & 5.6 & & 10.1 \\
\hline (5) & & 2.2 & & 1.5 & & 1.2 & & 1.4 & & 0.9 & & 0.9 \\
\hline \multicolumn{13}{|l|}{ Isoglycemic } \\
\hline Insulin & 31.0 & 60.3 & 12.2 & 39.3 & 18.8 & 21.0 & 4.4 & 15.5 & 14.3 & 5.5 & 31.5 & 7.9 \\
\hline (7) & 3.1 & 12.4 & 5.1 & 10.8 & 4.8 & 2.2 & 1.2 & 2.9 & 4.6 & 2.6 & 4.0 & 2.8 \\
\hline Insulin + fat & 34.1 & 38.2 & 13.6 & 20.3 & 20.5 & 17.9 & 6.1 & 7.3 & 14.4 & 10.6 & 33.7 & 9.1 \\
\hline (7) & 3.2 & 4.8 & 6.0 & 4.0 & 4.6 & 2.1 & 2.4 & 3.0 & 5.1 & 3.3 & 4.5 & 2.2 \\
\hline Insulin + glycerol & 28.6 & 76.3 & 13.4 & 53.6 & 15.2 & 22.7 & & & & & 28.6 & 9.9 \\
\hline (4) & 5.9 & 16.3 & 3.6 & 18.4 & 1.4 & 3.9 & & & & & 6.0 & 3.2 \\
\hline
\end{tabular}

Shown are mean \pm SEM. Basal glucose utilization data could not be obtained in euglycemic patients with NIDDM as insulin was infused to normalize their glucose concentrations. 

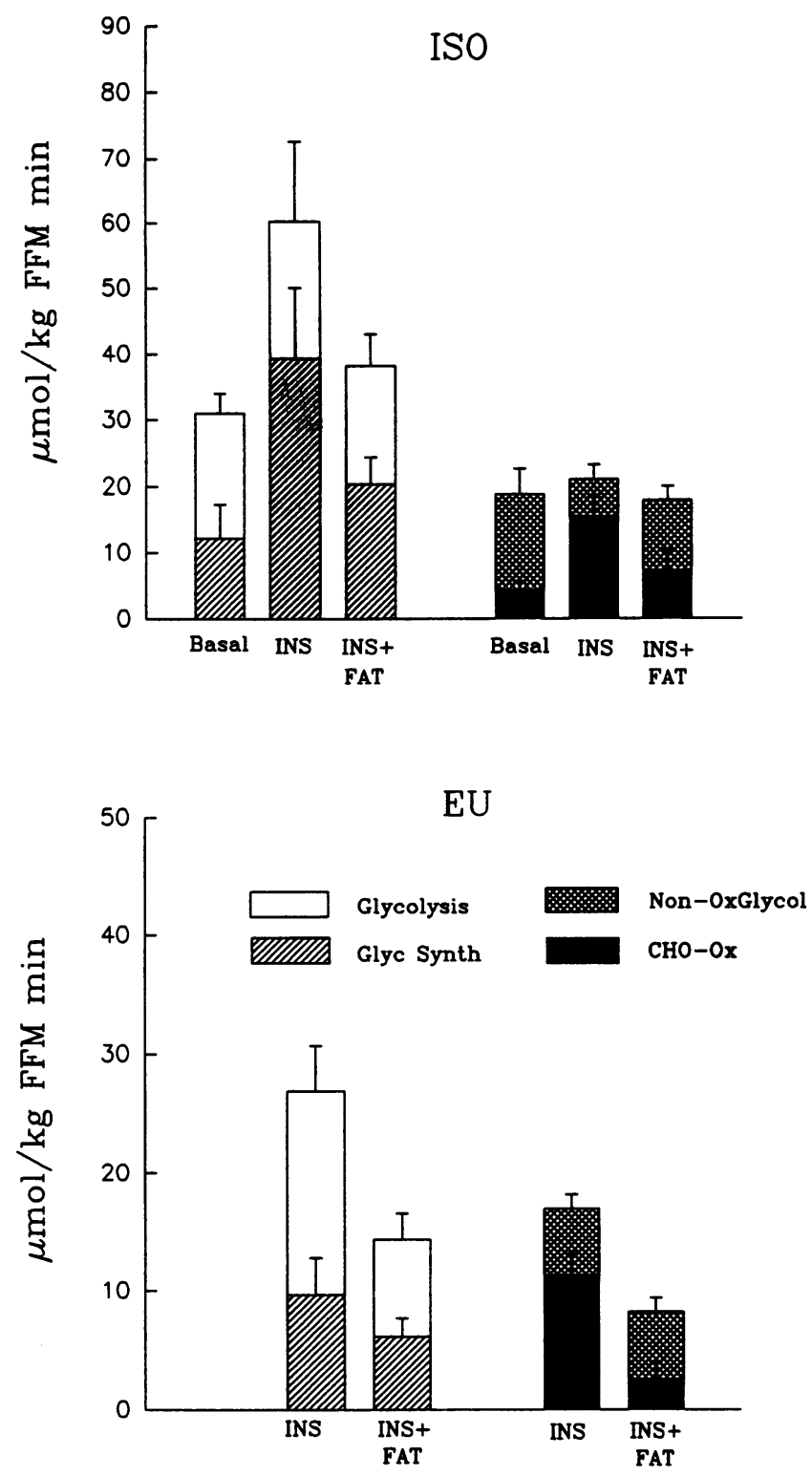

Figure 4. Effects of fat on intracellular glucose utilization. The upper panel shows isoglycemic-hyperinsulinemic clamp studies. The lower panel shows euglycemic-hyperinsulinemic clamp studies. The total length of bars on the left side of the figure represents rates of glucose uptake. The total length of bars on the right side of the figure represents rates of glycolysis.

Effect of fat on intracellular glucose utilization (Fig. 4, Table III). In isoglycemic-hyperinsulinemic clamps, fat reduced rates of glycogen synthesis from $39.3 \pm 10.8$ (insulin) and $53.6 \pm 18.4$ (insulin plus glycerol) to $20.3 \pm 4.0 \mu \mathrm{mol} / \mathrm{kg}$ FFM per min $(P<0.02)$. During euglycemic-hyperinsulinemic clamps, fat reduced glycogen synthesis from $9.7 \pm 3.1$ to $6.2 \pm 1.5$ $\mu \mathrm{mol} / \mathrm{kg}$ FFM per min (NS).

During euglycemic-hyperinsulinemic clamps, fat reduced rates of glycolysis from $21.0 \pm 2.2$ (insulin) and $22.7 \pm 3.9$ (insulin plus glycerol) to $17.9 \pm 2.1 \mu \mathrm{mol} / \mathrm{kg}$ FFM per min ( $P$ $<0.05$ ). During euglycemic-hyperinsulinemic clamps, fat reduced rates of glycolysis from $17.3 \pm 1.2$ to $8.2 \pm 1.2 \mu \mathrm{mol} / \mathrm{kg}$ FFM per min $(P<0.01)$.

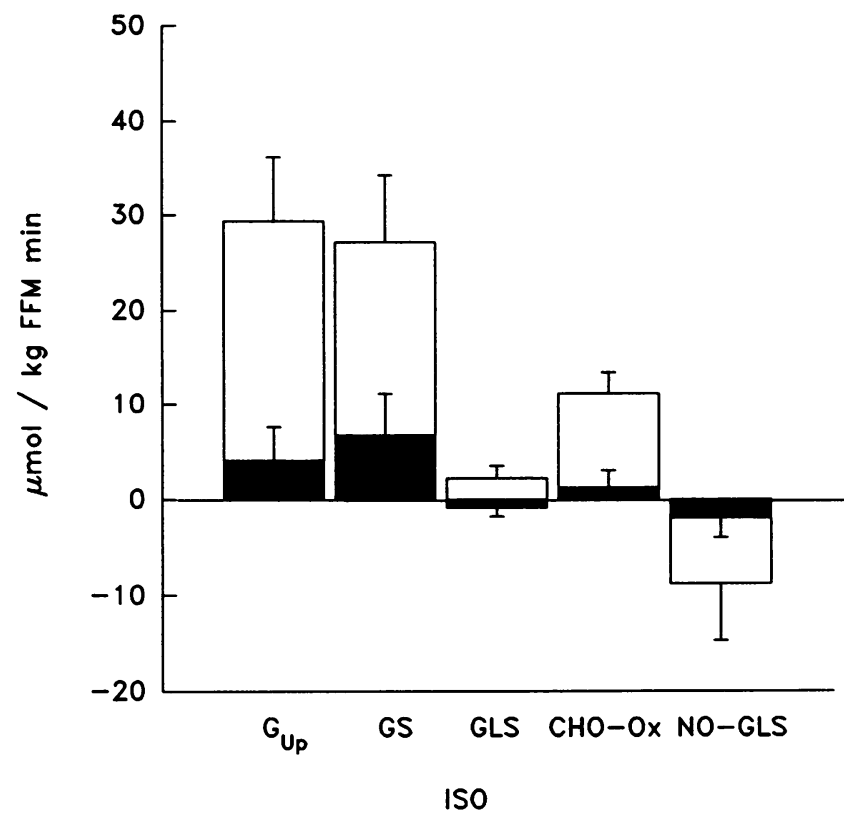

Figure 5. Effect of fat on rates of insulin stimulated glucose uptake $\left(G_{u p}\right)$, glycogen synthesis $(G S)$, glycolysis $(G L S)$, CHO oxidation $(\mathrm{CHO}-\mathrm{OX})$, and nonoxidative glycolysis $(\mathrm{NO}-\mathrm{GLS})$ in patients with NIDDM during isoglycemic clamping $(n=7)$. The total lengths of bars represent insulin stimulated values (total-basal) after $4 \mathrm{~h}$ of insulin infusion; solid bars represent insulin stimulated values after $4 \mathrm{~h}$ of insulin plus fat infusions. Positive values indicate insulin-mediated stimulation, negative values indicate inhibition.

Fat reduced rates of $\mathrm{CHO}$ oxidation from $15.5 \pm 2.9$ to $7.3 \pm 3.0 \mu \mathrm{mol} / \mathrm{kg}$ FFM per $\min (P<0.01)$ in isoglycemichyperinsulinemic clamps and from $11.4 \pm 1.8$ to $2.6 \pm 1.4 \mu \mathrm{mol} /$ kg FFM per $\min (P<0.01)$, in euglycemic-hyperinsulinemic clamps.

Fat increased rates of nonoxidative glycolysis from $5.5 \pm 2.6$ to $10.6 \pm 3.3 \mu \mathrm{mol} / \mathrm{kg}$ FFM per $\min (P<0.05)$ in isoglycemic patients, while it had no effect in euglycemic patients $(5.9 \pm 1.3$ to $5.6 \pm 0.9 \mu \mathrm{mol} / \mathrm{kg}$ FFM per $\min$ ).

Since fat appeared to affect selectively insulin-stimulated processes, we analyzed its effects on the insulin-stimulated part (total-basal) of glucose uptake and intracellular glucose utilization. This was only possible for the isoglycemic studies because, as pointed out above, basal flux rates could not be obtained in the euglycemic studies. As seen in Fig. 5, fat rather uniformly reduced the insulin effect on rates of glucose uptake $(-86 \%)$, glycogen synthesis $(-75 \%)$, glycolysis $(-140 \%)$, CHO oxidation $(-90 \%)$, and nonoxidative glycolysis $(-77 \%)$.

Effect of fat on hepatic glucose production (Table III). Postabsorptive hepatic glucose production (HGP) was 31.5 \pm 4.0 (before insulin) and 28.6 \pm 6.0 (before insulin plus glycerol) $\mu \mathrm{mol} / \mathrm{kg}$ FFM per min. Insulin-suppressed rates of HGP during isoglycemia were $7.9 \pm 2.8$ (insulin) and 9.9 \pm 3.2 (insulin plus glycerol) $\mu \mathrm{mol} / \mathrm{kg}$ FFM per min. Insulin-suppressed HGP during euglycemia was $10.1 \pm 0.9 \mu \mathrm{mol} / \mathrm{kg}$ FFM per min.

Fat infusion increased HGP during euglycemic clamping (from 3.9 to $10.1 \mu \mathrm{mol} / \mathrm{kg}$ FFM per min $P<0.05$ ). During isoglycemic clamping the increase in HGP (from 7.9 to 9.1 $\mu \mathrm{mol} / \mathrm{kg}$ FFM per min, NS) was not statistically significant. 
Moreover, a similar increase occurred with infusion of glycerol without fat (from 7.9 to $9.9 \mu \mathrm{mol} / \mathrm{kg}$ FFM per min, NS).

\section{Discussion}

Inhibition of glucose uptake by fat. The results of this study showed that in patients with NIDDM, fat inhibited total (basal plus insulin stimulated or basal plus insulin and glycerol stimulated) glucose uptake during isoglycemic clamping by 37 and $50 \%$, respectively, and by $46 \%$ during euglycemic clamping. These effects were similar to results previously reported in nondiabetic subjects (3-5). Fat did not, however, impair insulin stimulation of leg blood flow. To the extent that leg blood flow was representative of blood flow to muscle in general, this indicated that the fat-induced insulin resistance was not a vascular phenomenon (26) but occurred at the cellular level. Our findings were in disagreement with three other reports which failed to observe inhibition of insulin-stimulated glucose uptake during intravenous infusion of fat in patients with NIDDM (79 ). The discrepancy can be explained by a crucial difference in the experimental study designs. We have recently demonstrated that the inhibitory effect of fat on glucose uptake developed after 3-4 $h(3,5)$. The length of fat plus insulin infusion was only $2 \mathrm{~h}$ in the other three studies (7-9) which presumably was too short for the inhibitory effect of fat to develop.

Fat selectively inhibits insulin stimulated glucose uptake. The $40-50 \%$ fat induced inhibition of total (basal plus insulin stimulated) glucose uptake amounted to a near complete reduction in the insulin stimulated part of glucose uptake during isoglycemic clamps (Fig. 2). The nonsuppressed part consisted of basal, postabsorptive glucose uptake. In addition, we have demonstrated (Fig. 1) that fat did not inhibit glucose uptake under basal hyperglycemic $(\sim 11 \mathrm{mM})$ conditions in patients with NIDDM. We have previously shown that fat infusions did not inhibit glucose uptake under basal euglycemic conditions $(\sim 5 \mathrm{mM})$ in nondiabetic subjects (27). Together, these data supported the concept that fat selectively inhibited the insulin stimulated part of glucose uptake.

Effects of fat on intracellular glucose utilization. Since fat appeared to interfere selectively with insulin action, we analyzed its effect on the insulin stimulated part of glucose utilization. In the isoglycemic clamp studies, we found a surprising similarity of inhibition by fat of insulin stimulation of all major pathways of $\mathrm{CHO}$ utilization including glucose uptake, glycogen synthesis, glycolysis, oxidation, and nonoxidative glycolysis (Figs. 4 and 5). The reason for this uniform inhibition of different insulin actions was not clear. The possibility of a primary defect involving glucose entrance into cells, i.e., glucose transport and/or phosphorylation was supported by the proportional inhibition of glucose uptake, glycogen synthesis, and glycolysis and by previous findings in nondiabetic subjects, showing that the defect in glucose uptake, which appeared after $4 \mathrm{~h}$ of fat infusion, was associated with normal muscle glycogen synthase activity (5). Another explanation for the proportional inhibition of all glucose pathways would be a fat-produced defect early in insulin signal transduction affecting many insulin actions.

Therefore, it appeared that there were at least three independent fat-induced defects; an early, quantitatively minor defect $(4,28,29)$ of $\mathrm{CHO}$ oxidation which was first described by Randle et al. (30) and which has since been widely confirmed $(5,7,9,31)$; a second, major defect involving glucose transport and/or phosphorylation and a third defect, which we had reported previously, involving muscle glycogen synthase activity which developed after $4 \mathrm{~h}$ of fat infusion (5).

Nonoxidative glycolysis. Independent determination of rates of glycolysis and of $\mathrm{CHO}$ oxidation allowed estimation of rates of nonoxidative glycolysis which consists essentially of lactate and alanine fluxes (32). The results showed that $\sim 76 \%$ of the postabsorptive glycolytic flux in isoglycemic patients with NIDDM entered nonoxidative glycolysis while the remaining $24 \%$ was oxidized. Insulin-stimulated $\mathrm{CHO}$ oxidation more than threefold (to $74 \%$ of glycolytic flux). Since insulin did not significantly increase glycolytic flux, the increase in CHO oxidation occurred essentially at the expense of nonoxidative glycolysis. Fat reversed the effects of insulin, i.e., it increased nonoxidative glycolysis. In euglycemic-hyperinsulinemic clamp studies, the fat-mediated reduction in CHO oxidation was associated with a similar reduction in glycolysis and hence, no change in nonoxidative glycolysis. These results suggested that changes in CHO oxidation did not affect glycolytic flux but rather altered its distribution into oxidation or lactate/alanine formation. This may explain why the early inhibition of $\mathrm{CHO}$ oxidation by fat failed to affect glucose uptake.

Based on the widely held belief that rates of nonoxidative glycolysis are negligible, it has been customary to estimate rates of glycogen synthesis as nonoxidative glucose uptake (glucose uptake minus $\mathrm{CHO}$ oxidation). This method does not consider nonoxidative glycolysis and can result in substantial overestimation of glycogen synthesis (estimated as nonoxidative glucose uptake). For instance, in the present study, glycogen synthesis in isoglycemic patients after an overnight fast was $12.2 \mu \mathrm{mol} /$ kg FFM per min. Estimated as nonoxidative glucose uptake, however, it would have been more than two times higher (26.6 $\mu \mathrm{mol} / \mathrm{kg}$ FFM per min).

Hepatic glucose production. Postabsorptive rates of HGP were higher in patients with NIDDM than in previously reported normal controls ( 31,34 , and 29 vs $14 \mu \mathrm{mol} / \mathrm{kg}$ FFM per min) (5), while suppression of HGP by hyperinsulinemia appeared to be normal. Similar results have been reported by others (33). Normal suppression of HGP, however, did not exclude hepatic insulin resistance, since the clamp insulin concentrations $(\sim 1,000 \mathrm{pM})$ were $\sim 5$ times higher than the normal $\mathrm{ED}_{50}$ for insulin suppression of HGP (34). Fat increased HGP during insulin infusion in euglycemic and isoglycemic patients (from 3.9 and 7.9 to 10.1 and $9.1 \mu \mathrm{mol} / \mathrm{kg}$ FFM per min respectively). However, infusion of Liposyn II resulted not only in increased FFA but also in increased plasma glycerol concentrations (as a result of lipolysis and of glycerol present in the fat emulsion). When plasma glycerol levels, comparable to those seen during fat/heparin infusions, were reproduced by infusion of insulin together with glycerol, HGP increased to the same extent as during fat/heparin infusions. Hence, the cause for the increase in HGP during fat infusion appeared to be the increased availability of glycerol, which is known to be an excellent substrate for gluconeogenesis $(35,36)$.

Metabolic defects in NIDDM not related to fat. Comparing euglycemic and isoglycemic diabetic patients with normal controls from a previous study (5) under comparable low plasma FFA conditions, revealed several abnormalities not related to fatty acids. First, as has been shown in numerous studies (for review see reference 37 ), total stimulated glucose uptake in euglycemic patients was less than half (47\%) compared to nondiabetic controls. Thus, whereas our data indicated that high 
but physiologic plasma FFA concentrations $(\sim 1,000 \mu \mathrm{M})$ in patients with NIDDM abolished insulin stimulated glucose uptake, they also showed that some of the insulin resistance in these patients was unrelated to fatty acids.

Second, rates of glycogen synthesis in euglycemic diabetic patients were decreased to an even greater degree than rates of glucose uptake $(-72$ vs $-53 \%)$. This observation was in agreement with reports by others showing decreased rates of nonoxidative glucose uptake or decreased glycogen synthase activity in patients with $\operatorname{NIDDM}(32,38)$. On the other hand, rates of glycolysis $(-17 \%)$ and $\mathrm{CHO}$ oxidation $(-27 \%)$ were less inhibited than rates of glucose uptake $(-53 \%)$. We attributed this to shunting of glucose away from glycogen synthesis and into glycolysis and $\mathrm{CHO}$ oxidation.

In contrast to findings by Thorburn et al. (39) and Del Prato et al. (40) but in agreement with reports from several other groups (41-43), we found that total stimulated rates of $\mathrm{CHO}$ oxidation were normal in euglycemic and isoglycemic patients with NIDDM. The reason for this discrepancy was not clear. It may have been due to heterogeneity of the patients with NIDDM, as Thorburn et al. and Del Prato et al. studied nonobese, while we studied obese patients. Moreover, Del Prato et al. reported only marginally lower oxidation rates in patients with NIDDM during hyperinsulinemic clamping compared to controls $(16.7 \pm 0.6$ vs $19.5 \pm 0.8 \mu \mathrm{mol} / \mathrm{kg}$ FFM per min) and did not measure the insulin stimulated part of $\mathrm{CHO}$ oxidation but instead calculated it using assumed basal rates of $\mathrm{CHO}$ oxidation (40).

Summary and clinical relevance. This study showed that fat infusion in patients with NIDDM did not affect basal postabsorptive glucose uptake, but selectively inhibited insulin stimulated glucose uptake. The fat mediated inhibition of the insulin stimulated part of glucose uptake appeared to be dose dependent and was near $100 \%$ at high physiologic FFA concentrations $(\sim 1,000 \mu \mathrm{M})$. This effect could account for much but not all of the peripheral insulin resistance in these patients who were partially insulin resistant even at very low $(<100 \mu \mathrm{M})$ plasma FFA concentrations.

Proportional inhibition of glucose uptake, glycogen synthesis, and glycolysis suggested that fat caused a major defect involving glucose transport and/or phosphorylation.

These data suggested a significant role for fatty acids in the pathogenesis of peripheral insulin resistance in NIDDM. The reciprocal relationship between plasma FFA and insulin-stimulated glucose uptake may be of particular importance in obese patients in whom therapy directed towards lowering of high plasma FFA concentrations should have beneficial effects on glucose tolerance.

\section{Acknowledgments}

We thank the nurses of the General Clinical Research Center and Dr. Jose Ruiz for assistance with the clinical studies; Maria Mozzoli and Karen Davis for technical assistance; and Constance Harris for typing the manuscript.

This study was supported by a Clinical Research Grant from the American Diabetes Association (G. Boden) and by National Institutes of Health grants R01-AG-07988 (G. Boden) and RR 00349 (General Clinical Research Center)

\section{References}

1. Sims, E. A. H., E. Danforth, Jr., E. S. Horton, G. A. Bray, J. A. Glennon, and L. B. Salans. 1973. Endocrine and metabolic effects of experimental obesity in man. Recent Prog. Horm. Res. 29:457-496.
2. Pascoe, W. S., and L. H. Storlien. 1990. Inducement by fat feeding of hyperglycemia in rats with abnormal $\beta$-cell function. Model for study of etiology and pathogenesis of NIDDM. Diabetes. 39:226-233.

3. Boden, G., F. Jadali, J. White, Y. Liang, M. Mozzoli, X. Chen, E. Coleman, and C. Smith. 1991. Effects of fat on insulin-stimulated carbohydrate metabolism in normal men. J. Clin. Invest. 88:960-966.

4. Kelley, D. E., M. Mokan, J.-A. Simoneau, and L. J. Mandarino. 1993. Interaction between glucose and free fatty acid metabolism in human skeletal muscle. J. Clin. Invest. 92:91-98.

5. Boden, G., X. Chen, J. Ruiz, J. V. White, and L. Rossetti. 1994. Mechanisms of fatty acid-induced inhibition of glucose uptake. J. Clin. Invest. 93:2438-2446.

6. Reaven, G. M., C. Hollenbeck, C.-Y. Jeng, M. S. Wu, and Y.-D. I. Chen. 1988. Measurement of plasma glucose, free fatty acid, lactate and insulin for 24 $h$ in patients with NIDDM. Diabetes. 37:1020-1024.

7. Bevilacqua, S., G. Buzzigoli, R. Bonadonna, L. S. Brandi, M. Oleggini, C. Boni, M. Geloni, and E. Ferrannini. 1990. Operation of Randle's cycle in patients with NIDDM. Diabetes. 39:383-389.

8. Saloranta, C., A. Franssila-Kallunki, A. Ekstrand, M.-R. Taskinen, and L. Groop. 1991. Modulation of hepatic glucose production by non-esterified fatty acids in type 2 (non-insulin-dependent) diabetes mellitus. Diabetologia. 34:409415.

9. Yki-Jarvinen, H., I. Puhakainen, C. Saloranta, L. Groop, and M.-R. Taskinen. 1991. Demonstration of a novel feedback mechanism between FFA oxidation from intracellular and intravascular sources. Am. J. Physiol. 260:E680-E689.

10. Bevilacqua, S., R. Bonadonna, G. Buzzigoli, C. Boni, D. Ciociaro, F. Maccari, M. A. Giorico, and E. Ferrannini. 1987. Acute elevation of free fatty acid levels leads to hepatic insulin resistance in obese subjects. Metab. Clin. Exp. 36:502-506.

11. Rossetti, L., Y.-T. Lee, J. Ruiz, S. C. Aldridge, H. Shamoon, and G. Boden. 1993. Quantitation of glycolysis and skeletal muscle glycogen synthesis in humans. Am. J. Physiol. 265:E761-E769.

12. Shimoyama, R., T. K. Ray, C. R. Savage, Jr., O. E. Owen, and G. Boden. 1984. In vivo and in vitro effects of antiinsulin receptor antibodies. J. Clin. Endocrinol. \& Metab. 59:916-923.

13. Molina, J. M., A. D. Baron, S. V. Edelman, G. Brechtel, P. Wallace, and J. M. Olefsky. 1990. Use of a variable tracer infusion method to determine glucose turnover in humans. Am. J. Physiol. 258:E16-E23.

14. Steele, R., J. S. Wall, R. C. DeBodo, and N. Altszuler. 1956. Measurement of size and turnover rate of body glucose pool by the isotope dilution method. Am. J. Physiol. 187:15-24.

15. Rossetti, L., and A. Giaccari. 1990. Relative contribution of glycogen synthesis and glycolysis to insulin-mediated glucose uptake. A dose-response euglycemic clamp study in normal and diabetic rats. J. Clin. Invest. 85:17851792.

16. Owen, O. E., V. E. Trapp, G. A. Reichard, Jr., M. A. Mozzoli, R. Smith, and G. Boden. 1980. Effects of therapy on the nature and quantity of fuels oxidized during diabetic ketoacidosis. Diabetes. 29:365-372.

17. Tappy, L., O. E. Owen, and G. Boden. 1988. Effect of hyperinsulinemia on urea pool size and substrate oxidation rates. Diabetes. 37:1212-1216.

18. Sumner, D. S. Mercury strain-gauge plethysmography. 1982. In NonInvasive Diagnostic Techniques in Vascular Disease. E. F. Bernstein, editor. C. V. Mosby Co., St. Louis, MO, Toronto, London. 117-135.

19. Goldman, R. F., and E. R. Buskirk. 1961. Body volume measurement by underwater weighing: description of a method. In Techniques for Measuring Body Composition. Josef Brozek and Austin Henschel, editors. National Research Council, National Academy of Science. Washington, DC. 78-89.

20. Soeldner, J. S., and D. Slone. 1965. Critical variables in the radioimmunoassay of serum insulin using the double antibody technic. Diabetes. 14:771-779.

21. Harris, G., G. R. Faloona, and R. H. Unger. 1979. Glucagon. In Methods of Hormone Radioimmunoassay. B. M. Jaff and H. R. Behrmann, editors. Academic Press, Inc., New York, NY. 643-656.

22. Marsh, W. H., B. Fingerhut, and H. Miller. 1965. Automated and manual direct methods for the determination of blood urea. Clin. Chem. 11:624-627.

23. Hawk, P. 1947. The Kjeldahl method. In Practical Physiological Chemistry. Blakison, Toronto. 814-822.

24. Eggstein, M., and E. Kuhlmann. 1974. Triglyceride and glycerol. Determination after alkaline hydrolysis. In Methods of Enzymatic Analysis. H. U. Bergmeyer, J. Bergmeyer, and M. Grabl, editors. Academic Press, Inc., New York. $1825-1831$.

25. DeFronzo, R. A., E. Jacot, E. Jequier, E. Maeder, J. Wahren, and J. P. Felber. 1981. The effect of insulin on the disposal of intravenous glucose. Results from indirect calorimetry and hepatic and femoral venous catheterization. Diabetes. 30:1000-1007.

26. Laakso, M., S. V. Edelman, G. Brechtel, and A. D. Baron. 1990. Decreased effect of insulin to stimulate skeletal muscle blood flow in obese man: a novel mechanism for insulin resistance. J. Clin. Invest. 85:1844-1852.

27. Boden, G., and F. Jadali. 1991. Effects of lipid on basal carbohydrate metabolism in normal men. Diabetes. 40:686-692.

28. Thiebaud, D., R. A. DeFronzo, E. Jacot, A. Golay, K. Acheson, E. Maeder, 
E. Jequier, and J. P. Felber. 1982. Effect of long chain triglyceride infusion on glucose metabolism in man. Metab. Clin. Exp. 31:1128-1136.

29. Wolfe, B. M., S. Klein, E. J. Peters, B. F. Schmidt, and R. R. Wolfe. 1988. Effect of elevated free fatty acids on glucose oxidation in normal humans. Metab. Clin. Exp. 37:323-329.

30. Randle, P. J., P. B. Garland, E. A. Newsholme, and C. N. Hales. 1965. The glucose fatty acid cycle in obesity and maturity onset diabetes mellitus. Ann NY Acad. Sci. 131:324-333.

31. Ferrannini, E., E. J. Barrett, E. J., S. Bevilacqua, and R. A. DeFronzo. 1983. Effect of fatty acids on glucose production and utilization in man. J. Clin. Invest. 72:1737-1747.

32. Kelley, D., J. Reilly, T. Veneman, and L. Mandarino. 1990. Effects of insulin on skeletal muscle glucose storage, oxidation and glycolysis in humans Am. J. Physiol. 258:E923-E929.

33. DeFronzo, R. A. 1988. Lilly lecture. The triumvirate: $\beta$-cell, muscle, liver A collusion responsible for NIDDM. Diabetes. 37:667-687.

34. Groop, L. C., R. C. Bonadonna, S. Del Prato, K. Ratheiser, K. Zych, E. Ferrannini, and R. A. DeFronzo. 1989. Glucose and free fatty acid metabolism in non-insulin dependent diabetes mellitus: evidence for multiple sites of insulin resistance. J. Clin. Invest. 84:205-213.

35. Waldhausl, W., P. Bratusch-Marrain, S. Gasic, A. Korn, and P. Nowatony. 1982. Insulin production rate, hepatic insulin retention, and splanchnic carbohydrate metabolism after oral glucose ingestion in hyperinsulinemic type II (noninsulin-dependent) diabetes mellitus. Diabetologia. 23:6-15.

36. Consoli, A., N. Nurjahn, F. Capani, and J. Gerich. 1989. Predominant role of gluconeogenesis in increased hepatic glucose production in NIDDM. Diabetes. 38:550-556.

37. DeFronzo, R. A., R. C. Bonadonna, and E. Ferrannini. 1992. Pathogenesis of NIDDM. A Balanced Overview. Diabetes Care. 15:318-368.

38. Bogardus, C., S. Lillioja, K. Stone, and D. Mott. 1984. Correlation between muscle glycogen synthase activity and in vivo insulin action in man. J. Clin. Invest. 73:1185-1190.

39. Thorburn, A. W., B. Gumbiner, F. Bulacan, P. Wallace, and R. R. Henry. 1990. Intracellular glucose oxidation and glycogen synthase activity are reduced in non-insulin-dependent (Type II) diabetes independent of impaired glucose uptake. J. Clin. Invest. 85:522-529.

40. Del Prato, S., R. C. Bonadonna, E. Bonora, G. Gulli, A. Solini, M. Shank, and R. A. DeFronzo. 1993. Characterization of cellular defects of insulin action in type 2 (non-insulin-dependent) diabetes mellitus. J. Clin. Invest. 91:484-494.

41. Shulman, G. I., D. L. Rothman, T. Jue, P. Stein, R. A. DeFronzo, and R. G. Shulman. 1990. Quantitation of muscle glycogen synthesis in normal subjects and subjects with non-insulin dependent diabetes by ${ }^{13} \mathrm{C}$ nuclear magnetic resonance spectroscopy. N. Engl. J. Med. 322:223-228.

42. Kelley, D. E., and L. J. Mandarino. 1990. Hyperglycemia normalizes insulin-stimulated skeletal muscle glucose oxidation and storage in non-insulindependent diabetes mellitus. J. Clin. Invest. 86:1999-2007.

43. Butler, P. C., E. J. Kryshak, M. Marsh, and R. A. Rizza. 1990. Effect of insulin on oxidation of intracellularly and extracellularly derived glucose in patients with NIDDM. Evidence for primary defect in glucose transport and/or phosphorylation but not oxidation. Diabetes. 39:1373-1380. 